\title{
PENGARUH LEADER-MEMBER EXCHANGE TERHADAP KINERJA KARYAWAN MELALUI PERAN VARIABEL MEDIASI WORK ENGAGEMENT PADA PT. PERUSAHAAN LISTRIK NEGARA (PERSERO) AREA BENGKULU
}

\author{
Sely Justina ${ }^{1}$ \\ Sugeng Susetyo ${ }^{2}$ \\ Paulus Kananlua ${ }^{3}$ \\ ${ }^{1}$ Fakultas Ekonomi dan Bisnis, Universitas Bengkulu \\ ${ }^{2}$ Fakultas Ekonomi dan Bisnis, Universitas Bengkulu \\ ${ }^{3}$ Fakultas Ekonomi dan Bisnis, Universitas Bengkulu \\ selyjustina12@gmail.com
}

\begin{abstract}
Work Engagement is a partial mediator between Leader-Member Exchange and employee performance, so that employees with high Leader-Member Exchange and Work Engagement can develop further contribute to employee performance and advance through Work Engagement performance. The purpose of this study was to examines the effect of Leader-Member Exchange on performance with Work Engagement as a mediating variable at the PT. PLN (Persero) Bengkulu Area. The number of samples taken as many as 69 employees in . PLN (Persero) Bengkulu Area. Data obtained by distributing questionnaires were analyzed using mediated regression analysis. It was found that Leader-Member Exchange is positively effect Work Engagement, Leader-Member Exchange has positively impact on employee performance, Work Engagement has positively impact employee performance, and Work Engagement mediates the relationship between Leader-Member Exchange and employee performance.
\end{abstract}

Keywords: Leader-Member Exchange, Work Engagement, and Performance

\section{PENDAHULUAN}

Dalam menghadapi persaingan bisnis di era globalisasi, perusahaan dituntut untuk memberikan hasil yang optimal untuk mencapai visi dan misi perusahaan tersebut. Karyawan merupakan elemen yang sangat penting dalam suatu organisasi. Salah satu keberhasilan suatu organisasi bisa dilihat dari pencapaian kinerja karyawan. Keberhasilan dan kesuksesan kinerja suatu organisasi ditentukan oleh kualitas sumber daya manusianya yang meliputi pimpinan dan bawahan sehingga pemahaman dan kemampuan dalam menjalankan manajemen kinerja dapat berjalan maksimal (Wibowo, 2013). Kinerja adalah hasil kerja yang dicapai oleh seorang karyawan dalam melaksanakan pekerjaan sesuai dengan tanggung jawab yang diberikan perusahaan dilihat dari segi kualitas maupun kuantitas (Mangkunegara, 2013). Kontribusi karyawan 
bagi organisasi sangat penting karena karyawan adalah penghasil kerja bagi organisasi atau perusahaan. Apabila kinerja karyawan baik maka akan baik pula hasil yang didapatkan perusahaan. Kinerja perusahaan yang baik tidak terlepas dari peran pemimpin, dimana seorang pemimpin memiliki kecakapan untuk mempengaruhi orang lain untuk melakukan aktivitas tertentu sehingga mereka secara sukarela melaksanakannya demi tujuan organisasi. Kinerja karyawan tidak akan terlepas dari faktor - faktor yang mempengaruhinya. Salah satunya yaitu leader-member exchange. Leader-member exchange merupakan hubungan yang terjalin antara atasan dan bawahan yang saling mempengaruhi untuk meningkatkan kinerja keduanya dari waktu ke waktu, dalam diri mereka akan timbul rasa diterima dalam organisasi, dengan begitu mereka nantinya akan bekerja dengan sepenuh hati demi mencapai tujuan organisasi (Luthans, 2008).

Leader-member exchange (LMX) juga dapat meningkatkan kinerja karyawan karena perlakuan pemimpin yang baik terhadap karyawan juga akan mampu menciptakan perasaan sukarela pada diri karyawan untuk rela berkorban bagi organisasi. Hal ini membuktikan bahwa leader-member exchange berhubungan positif dengan kinerja. Jika hubungan yang terjalin baik antara pemimpin dan karyawan maka akan menciptakan rasa hormat, kepercayaan, rasa tanggung jawab yang tinggi terhadap pekerjaan dan loyalitas yang kuat antara atasan dan bawahan demi kemajuan organisasi. Studi Li et al. (2012) menemukan bahwa leader-member exchange menjadi prediktor work engagement dan berhubungan positif dengan kinerja. Dalam hubungan pertukaran berkualitas tinggi, supervisor sebagai pemimpin mendukung bawahan dengan memberikan kepercayaan dan dukungan emosional terhadap bawahan (Graen dan Uhl-Bien, 1995). Karyawan yang telah diberi kepercayaan dan dukungan dari atasan akan merasa lebih dihargai dan dibutuhkan oleh organisasi. Sehingga karyawan lebih antusias dalam bekerja dan berdedikasi tinggi terhadap pekerjaannya. Menurur Bakker dan Leiter (2010) work engagement memiliki fokus yang memungkinkan karyawan untuk mengerahkan seluruh kemampuan dan potensi yang dimiliki terhadap pekerjaannya serta mengabaikan tekanan dan kesulitan yang ada. Sehingga karyawan dengan tingkat LMX yang tinggi dapat mengembangkan work engagement yang kemudian dapat berkontribusi terhadap kinerja.

PT. Perusahaan Listrik Negara atau PT. PLN (Persero) merupakan perusahaan milik negara yang bertanggung jawab atas penyediaan kelistrikan di Indonesia. Sebagai salah satu Badan Usaha Milik Negara, PT. PLN (Persero) berkomitmen menjadi penunjang penyediaan tenaga listrik yang cukup, harga yang sesuai, handal dan mutu yang memadai. Oleh karena itu, PT. PLN (Persero) selalu berupaya untuk terus memperbaiki kinerja perusahaan dalam memberikan pelayanan yang optimal dan dapat memuaskan pelanggannya. Untuk meningkatkan kinerja PT. PLN (Persero) harus didukung oleh sumber daya manusia yang berkualitas, demi mewujudkan sumber daya manusia yang berkualitas dalam perusahaan, peranan pemimpin tentu sangat 
dibutuhkan dan memiliki andil yang cukup besar. Kemajuan organisasi sangat ditentukan oleh pemimpin yang disukai dan disegani oleh para karyawannya. Seorang pemimpin yang dapat mempengaruhi dan mengarahkan para karyawannya untuk bekerja dengan maksimal tentu akan memberikan pengaruh terhadap kinerja perusahaan dan peningkatan kualitas perusahaan.

Berdasarkan hal tersebut, tujuan penelitian ini adalah, (1) menguji pengaruh leader-member exchange pada kinerja karyawan PT. PLN (Persero) Area Bengkulu, (2) menguji pengaruh leader-member exchange terhadap work engagement karyawan PT. PLN (Persero) Area Bengkulu, (3) mwnguji pengaruh work engagement pada kinerja karyawan PT. PLN (Persero) Area Bengkulu, (4) menguji pengaruh leader-member exchange terhadap kinerja dengan work engagement sebagai variabel pemediasi pada karyawan PT. PLN (Persero) Area Bengkulu.

\section{TINJAUAN PUSTAKA}

\section{Kinerja}

Kinerja adalah suatu hasil pencapaian atas pelaksanaan tugas tertentu dalam rangka mewujudkan tujuan perusahaan (Simanjuntak, 2011:7). Sedangkan Mathis dan Jackson (2006:65) mengemukakan bahwa kinerja pada dasarnya apa yang telah dilakukan atau yang tidak dilakukan oleh karyawan pada saat bekerja. Apa yang dilakukan oleh karyawan dimaknai sebagai segala sesuatu yang harus dilakukan karyawan dan segala sesuatu yang tidak boleh dilakukan oleh karyawan juga bisa dikatakan sebagai kinerja. Berbagai usaha dilakukan organisasi untuk meningkatkan kinerja. Untuk menghasilkan kinerja yang baik seseorang harus mempunyai kemampuan dan kemauan. Kinerja yang baik dapat memberikan keuntungan bagi perusahaan dan karyawan itu sendiri. Menurut Dessler (2009) mendefinisikan kinerja sebagai prestasi kerja yakni perbandingan antara prestasi aktual karyawan dengan prestasi yang diharapkan dari karyawan. Maksud dari prestasi yang diharapkan adalah standar kerja yang telah ditetapkan oleh perusahaan.

\section{Indikator Kinerja}

Untuk mengukur tingkat pencapaian suatu standar yang telah ditetapkan perusahaan dapat dilihat hasil penelitian berdasarkan indikator dari variabel penelitian, yang bertujuan untuk mempermudah penilaian kinerja karyawan. Berikut ini beberapa indikator menurut Bangun (2012) indikator kinerja adalah :

1) Kualitas, memenuhi persyaratan tertentu agar dapat menghasilkan pekerjaan sesuai kualitas yang dituntut pekerjaan.

2) Kuantitas, menunjukkan jumlah pekerjaan yang dihasilkan individu sebagai standar pekerjaan.

3) Tanggung jawab, diukur melalui presepsi karyawan dalam melaksanakan tugas dan tanggung jawab yang diberikan. 
4) Ketepatan waktu, diukur dari presepsi karyawan mampu menyelesaikan pekerjaan sesuai dengan waktu yang telah ditetapkan.

5) Kemampuan bekerja sama, karyawan dapat bekerja sama dengan baik.

Sedangkan menurut William dan Anderson (1991) dimensi kinerja yaitu:

1.) Kinerja tugas merupakan sutu ukuran seberapa baik karyawan dalam melaksanakan tugas-tugas yang berkaitan dengan pekerjaannya dengan cara memenuhi persyaratan formal dari tugas-tugas tersebut yang kemudian dapat memenuhi harapan organisasi (William \& Anderson, 1991). Karyawan yang menunjukkan tingkat kinerja tugas yang diharapkan tentu akan mendapatkan umpan balik positif dari organisasi. kinerja tugas juga melibatkan penyelesaian tugas secara khusus untuk memenuhi persyaratan pekerjaan tertulis.

\section{Leader-Member Exchange}

Leader-member exchange diartikan sebagai kualitas hubungan timbal balik antara atasan dan bawahan agar dapat menghasilkan kinerja yang baik. Kualitas hubungan yang dimaksud adalah sejauh mana hubungan antara atasan dan bawahan dan bagaimana interaksinya dalam menjalankan aktivitas dalam perusahaan atau organisasi. Menurut Yukl (1998) Leader-member exchange merupakan hubungan yang terjalin antara atasan dan bawahan yang saling mempengaruhi untuk meningkatkan kinerja keduanya dari waktu ke waktu. Menurut Truckenbrodt (2000) fokus dari hubungan atasan dan bawahan dimaksudkan untuk memaksimalkan keberhasilan suatu organisasi melalui interaksi kedua belah pihak. Perlakuan pemimpin yang baik terhadap karyawan akan mampu menciptakan perasaan sukarela pada diri karyawan untuk bisa berkorban bagi organisasi.

\section{Dimensi Leader-Member Exchange}

Menurut Liden dan Maslyn (1998) menyatakan bahwa dimensi leader-member exchange dibagi menjadi 4 dimensi yaitu:

1) Affection, diukur dari kepedulian yang timbul antara atasan dan bawahan yang terbentuk pada daya tarik individu, bukan hanya nilai profesionalnya saja.

2) Loyality, menyangkut suatu kesetiaan penuh terhadap seseorang secara konsisten.

3) Contribution, diukur dari presepsi yang berorientasi pada tugas di tingkat tertentu antara setiap anggota organisasi untuk mencapai tujuan bersama.

4) Professional Respect, dilihat dari hubungan yang baik antara atasan dan bawahan melebihi apa yang telah ditetapkan dalam organisasi.

\section{Work Engagement}

Schaufeli et al. (2013) mendefinisikan work engagement sebagai unik positif terkait dengan pekerjaan yang memberikan semangat, dedikasi, dan penyerapan 
kepada karyawan berdasarkan rasa keterikatan dalam perusahaan. Karyawan yang terikat dalam suatu pekerjaan akan memiliki tingkat energi dan semangat yang tinggi, dedikasi terhadap pekerjaan, dan menjadi terinspirasi pada pekerjaannya. Karyawan merasa engage ketika karyawan terikat secara fisik, kognitif dan emosional, yang ditunjukkan melalui keterlibatan karyawan didalam tugas-tugasnya. Menurut Gallup (2013) karyawan yang memiliki keterikatan akan bekerja secara konsisten pada level tinggi. Karyawan akan berkontribusi secara positif terhadap organisasi dan berkomitmen terhadap pekerjaan yang diberikan.

\section{Dimensi Work Engagement}

Dimensi - dimensi work engagement dikemukakan berbeda - beda oleh para peneliti terdahulu. Dimensi dari work engagement yang dikemukakan oleh Schaufeli, et al. (2006) yaitu :

1) Vigor, diukur dari tingkat semangat dan energi karyawan dalam melaksanakan tugas saat bekerja.

2) Dedication, mengacu pada keterikatan karyawan dengan rasa antusias dalam bekerja, selalu tertantang atas pekerjaannya.

3) Absorption, diukur dari kesungguhan dan kerelaan karyawan dalam bekerja untuk organisasi.

\section{METODE PENELITIAN Jenis Penelitian}

Jenis penelitian ini adalah kualitatif, yaitu penelitian yang mengumpulkan data secara langsung dari respoden dengan menggunakan kuesioner dan item - item pertanyaan pada kuesioner, biasanya berhubungan langsung dengan skala perilaku atau pendapat seseorang. Menurut Sugiyono (2014) menyatakan bahwa metode survei digunakan untuk memperoleh data dari tempat tertentu secara alamiah (bukan buatan), akan tetapi penulis melakukan perlakuan dalam mengumpulkan data, misalnya dengan menggunakan kuesioner, wawancara terstruktur dan lainnya.

\section{Metode Pengumpulan Data}

Metode pengumpulan data yang digunakan dalam penelitian ini adalah dengan menggunakan kuesioner, dimana kuesioner merupakan beberapa daftar pernyataan dan dalam jawaban biasanya berupa tingkatan (jenjang) jawaban seperti mulai dari setuju sampai tidak setuju. Skala pengukuran yang digunakan adalah skala Likert. Menurut Sugiyono (2014) digunakannya skala likert, "untuk mengukur sikap, pendapat, dan persepsi seseorang atau sekelompok orang tentang fenomena sosial". 


\section{Metode Pengambilan Sampel Populasi}

Populasi merupakan wilayah generalisasi yang ditetapkan oleh peneliti terdiri dari objek atau subjek yang mempunyai kualitas dan karakteristik tertentu untuk dipelajari dan kemudian ditarik kesimpulannya (Sugiyono, 2014). Populasi dalam penelitian ini adalah seluruh karyawan PT. PLN (Persero) area Bengkulu.

\section{Sampel}

Sampel merupakan bagian dari jumlah dan karateristik yang dimiliki oleh populasi (Sugiyono, 2014). Teknik pengambilan sampel pada penelitian ini menggunakan sensus yaitu keseluruhan populasi dijadikan sampel (Sekaran, 2006). Dalam penelitian ini seluruh anggota populasi sebanyak 69 karyawan dijadikan sampel pada PT. PLN (Persero) area Bengkulu.

\section{Uji Validitas dan Uji Reliabilitas Uji Validitas}

Uji validitas digunakan untuk mengukur sah (valid) atau tidaknya kuesioner. Menurut Sekaran dan Bougie (2016) instrumen dikatakan valid apabila instrumen tersebut dapat digunakan untuk mengukur apa yang seharusnya diukur, dikatakan valid apabila pertanyaan pada angket mampu mengungkapkan sesuatu yang tidak diketahui. Uji validitas ini jenis validitas konstruk yaitu jenis validitas yang menunjukkan bahwa instrumen pengukuran mengukur secara valid konsep yang diuji dalam model penelitian yang ditunjukkan dengan korelasi yang kuat antar indikator pengukur disuatu konstruk ( Abdillah dan Jogiyanto, 2015 ). Item - item pertanyaan secara empiris dianalisis oleh koefisien validitas yang disebut corected item atau total correlation atau koefisien korelasi item koreksi ( $r$ hitung). Setiap item pertanyaan dikatakan valid dan dapat diterima jika $r$ hitung $>r$ tabel (dengan $n-2, \alpha=0,05$ ) dan sebaliknya jika $r$ hitung $<r$ tabel maka butir pertanyaan tersebut dinyatakan tidak valid, untuk mengukur kesalahan dapat dilihat item - item yang dimiliki $r$ tabel 0,236. Jika korelasi skor item $<0,236$ maka butir instrumen itu dinyatakan tidak valid.

\section{Uji Reliabilitas}

Pengujian reliabilitas dilakukan untuk mengukur bahwa instrumen yang digunakan pada penelitian benar-benar menghasilkan data yang bebas dari kesalahan. Reliabilitas menunjukkan akurasi, konsistensi dan ketepatan suatu alat ukur dalam melakukan pengukuran (Sekaran, 2006). Teknik yang digunakan untuk mengetahui tingkat reliabel suatu instrumen dengan menggunakan cronbach's alpha, peneliti menggunakan program SPSS 16.0 for window. Perhitungan menggunakan skor alpha karena instrumen penelitian ini berbentuk kuesioner dan skala bertingkat. Sekaran 
(2006) mengelompokkan tingkatan reliabilitas dengan kriteria, jika nilai diatas 0,8 reliabilitas dianggap baik, 0,7 reliabilitas dapat diterima dan apabila nilai kurang dari 0,6 reliabilitas kurang baik.

\section{Teknik Analisis Data}

Metode analisis data yang digunakan dalam penelitian ini adalah metode analisis data kuantitatif. Untuk menguji hipotesis analisis data selanjutnya menggunakan pendekatan regresi termediasi atau mediated regression approach. Pengujian peran mediasi dalam pemodelan hubungan yang dihipotesiskan dilakukan melalui beberapa tahapan yang disarankan Baron dan Kenny (1986). Terdapat empat tahapan dalam pengujian peran mediasi variabel work engagement yang diujikan dalam penelitian ini.

Baron \& Kenny (1986) mengusulkan empat tahap pendekatan tersebut untuk melakukan pengujian analisis regresi dalam pengujian peran variabel termediasi. Seperti yang diketahui pada pengujian variabel penelitian ini bahwa pengaruh leadermember exchange terhadap kinerja karyawan yang dimediasi work engagement. Peran mediasi tersebut dibuktikan keabsahannya. Empat tahapan pengujian peran mediasi:

1. Tahapan Pertama :

Melakukan analisis regresi sederhana pengaruh antara variabel $\mathrm{X}$ leader-member exchange terhadap variabel $Y$ kinerja karyawan.

$$
Y=\beta 0+\beta 1 X+e
$$

2. Tahapan Kedua :

Melakukan analisis regresi sederhana pengaruh antara variabel $\mathrm{X}$ leader-member exchange terhadap variabel $\mathrm{M}$ work engagement.

$$
M=\beta 0+\beta 1 X+e
$$

3. Tahapan ketiga :

Melakukan analisis regresi sederhana pengaruh antara variabel $\mathrm{M}$ work engagement terhadap variabel $Y$ kinerja karyawan.

$$
Y=\beta 0+\beta 1 M+e
$$

4. Tahapan keempat :

Melakukan analisis regresi berganda variabel X leader-member exchange dan $\mathrm{M}$ work engagement terhadap $\mathrm{Y}$ kinerja karyawan.

$$
Y=\beta 0+\beta 1 X+\beta 1 M+e
$$




\section{HASIL PENELITIAN}

Pengaruh Leader-Member Exchange Terhadap Kinerja

Berdasarkan hasil penelitian, diketahui bahwa variabel leader-member exchange berpengaruh positif dan signifikan terhadap kinerja, dengan koefisien $\beta 0,803$ dan nilai t hitung variabel leader-member exchange sebesar 11,018 dengan tingkat signifikansi $0,000<0,05$. Langkah pertama ini mendukung hipotesis 1 (pertama) yang memberikan hasil kesimpulan bahwa leader-member exchange berpengaruh terhadap kinerja. Hal tersebut membuktikan bahwa semakin tinggi leader-member exchange yang diberikan oleh perusahaan maka akan semakin tinggi kinerja karyawan.

Berpengaruhnya variabel leader-member exchange terhadap kinerja karyawan pada PT. PLN (Persero) Area Bengkulu dapat dilihat pada tanggapan responden yang memberikan rata-rata baik yaitu 4,11 yang dikategorikan baik. Nilai rata-rata tertinggi terdapat pada dimensi professional respect dengan skor 4,23 yang tergolong sangat baik. Hal ini menunjukkan bahwa hubungan yang terjalin antara atasan dan bawahan pada PT. PLN (Persero) Area Bengkulu sudah melebihi apa yang telah ditetapkan perusahaan, maksudnya hubungan yang terjalin tidak hanya sebatas rekan kerja saja, adanya sikap saling menghargai antara pemimpin dan karyawan atas kemampuan dan kompetensi yang dimiliki sudah baik.

\section{Pengaruh Leader-Member Exchange Terhadap Work Engagement}

Berdasarkan hasil penelitian, diketahui bahwa variabel leader-member exchange berpengaruh positif terhadap work engagement, dengan koefisiesn nilai $\beta 0,668$ dan nilai $\mathrm{t}$ hitung variabel persepsi dukungan organisasi sebesar 7,339 dengan nilai signifikansi $0,000<0,05$. Langkah kedua ini mendukung hipotesis 2 (kedua) yang memberikan hasil kesimpulan bahwa leader-member exchange berpengaruh terhadap tingkat work engagement karyawan. Hal tersebut dapat disimpulkan bahwa semakin tinggi leader-member exchange yang diberikan perusahaan, maka akan meningkatkan work engagement pada karyawan.

Berpengaruhnya leader-member exchange (LMX) dari segi afeksi, kontribusi, loyalitas dan respek profesional juga dapat terlihat pada dimensi absorption dengan rata-rata tertinggi yaitu 4,02. Hal ini berarti, pemimpin PT. PLN (Persero) Area Bengkulu mampu mendorong karyawan untuk menunjukkan kesungguhan dan kerelaan karyawan dalam bekerja demi organisasi.

\section{Pengaruh Work Engagement Terhadap Kinerja}

Berdasarkan hasil penelitian, diketahui bahwa variabel work engagement berpengaruh positif terhadap kinerja, dengan koefisien nilai $\beta 0,746$ dan nilai t hitung variabel organizatioan/ citizenship behaviour sebesar 9,160 dengan tingkat signifikansi sebesar $0,000<0,05$. Langkah ketiga ini mendukung hipotesis 3 (ketiga) yang memberikan hasil kesimpulan bahwa work engagement berpengaruh terhadap kinerja. 
Pernyataan ini dapat ditarik kesimpulan bahwa semakin tinggi tingkat work engagement karyawan maka akan meningkatkan kinerja karyawan.

Berdasarkan hasil tanggapan responden pada variabel work engagement memperoleh rata-rata nilai sebesar 3,94, dimana angka tersebut masih termasuk dalam kategori baik. Hal ini menunjukkan bahwa karyawan PT. PLN (Persero) Area Bengkulu selalu berusaha bersemangat, antusias dalam mengerjakan tugas dan mendedikasikan diri terhadap pekerjaannya, serta cenderung mengerahkan seluruh kemampuan yang dimiliki agar menghasilkan kinerja yang memuaskan. Hal ini tentu akan berdampak pada perusahaan dengan meningkatnya kinerja yang dihasilkan perusahaan.

Sikap-sikap yang ditunjukkan oleh karyawan tentang work engagement yang tinggi ini sesuai dengan pernyataan Bakker dan Demerouti (2007) yaitu karyawan akan cenderung lebih produktif, kreatif pada saat bekerja dan ingin bekerja ekstra melebihi apa yang menjadi tanggung jawabnya. Work engagement yang tinggi pada PT. PLN (Persero) Area Bengkulu mendorong karyawan lebih termotivasi dalam bekerja serta bersemangat dan antusias, serta cenderung mengerahkan seluruh kemampuan demi tercapainya tujuan organisasi.

Pengaruh Leader-Member Exchange Terhadap Kinerja Karyawan Melalui Variabel Mediasi Work Engagement

Berdasarkan persamaan regresi, dapat diketahui bahwa variabel work engagement dinyatakan sebagai variabel mediasi parsial (partial mediation) karena setelah memasukkan variabel work engagement, pengaruh variabel leader-member exchange terhadap kinerja karyawan menurun menjadi $\beta=0,550$ dari sebelumnya $\beta=$ 0,803 tetapi tidak menjadi nol $(\beta \neq 0)$ atau pengaruh variabel leader-member exchange terhadap kinerja karyawan yang tadinya signifikan ( $p$-value $0,000<0,05$ ) sebelum memasukkan variabel work engagement menjadi tetap signifikan ( $p$-value 0,000 <0,05 ) setelah memasukkan variabel mediasi work engagement ke model persamaan regresi.

Pengujian hipotesis keempat membuktikan bahwa work engagement sebagai pemediasi pengaruh antara leader-member exchange terhadap kinerja karyawan secara parsial ( partially mediation ) seperti yang telah diuraikan sebelumnya diatas.

Penelitian ini mendukung penelitian yang telah dilakukan oleh $\mathrm{Li}$, et al. (2012) yang menyebutkan bahwa leader-member exchange menjadi prediktor work engagement dan tekait secara positif terhadap kinerja karyawan. Hal ini juga diperkuat oleh hasil temuan Breevaart, et al. (2015) yang menjelaskan bahwa work engagement memediasi hubungan antara leader-member exchange terhadap kinerja karyawan. 


\section{KESIMPULAN DAN SARAN Kesimpulan}

1. Leader-member exchange berpengaruh positif dan signifikan terhadap kinerja karyawan pada PT. PLN (Persero) Area Bengkulu. Hal ini menunjukkan bahwa semakin erat hubungan timbal balik yang terjalin antara supervisor dan karyawan maka akan meningkatkan kinerja karyawan PT. PLN (Persero) Area Bengkulu.

2. Leader-member exchange berpengaruh positif dan signifikan terhadap work engagement karyawan PT. PLN (Persero) Area Bengkulu. Hal ini menunjukkan bahwa semakin baik hubungan antara atasan dan bawahan mampu meningkatkan work engagement pada karyawan PT. PLN (Persero) Area Bengkulu.

3. Work engagement berpengaruh positif dan signifikan terhadap kinerja karyawan PT. PLN (Persero) Area Bengkulu. Hal ini menunjukkan bahwa semakin tinggi rasa engagement pada karyawan maka semakin baik pula kinerja yang dihasilkan karyawan PT. PLN (Persero) Area Bengkulu.

4. Adanya pengaruh yang positif dan signifikan antara leader-member exchange dan kinerja karyawan PT. PLN (Persero) Area Bengkulu yang dimediasi oleh variabel work engagement. Hal ini membuktikan bahwa work engagement memediasi leader-member exchange sehingga menmiliki pengaruh positif terhadap kinerja karyawan PT. PLN (Persero) Area Bengkulu.

\section{Saran}

Berdasarkan dari hasil kesimpulan penelitian, bebrapa saran yang dapat diberikan berkaitan dengan leader-member exchange, work engagement dan kinerja karyawan pada PT. PLN (Persero) Area Bengkulu adalah :

1. Bagi PT. PLN (Persero) Area Bengkulu, leader-member exchange merupakan faktor penting dalam meningkatkan kinerja perusahaan. Hal yang perlu menjadi perhatian yaitu masih ada karyawan yang belum merasa setia sepenuhnya terhadap atasan secara konsisten hal ini terlihat pada rendahnya dimensi loyalty pada variabel leader-member exchange. Oleh karena itu disarankan bagi seluruh karyawan PT. PLN (Persero) Area Bengkulu agar lebih meningkatkan hubungan yang baik antar sesama karyawan maupun dengan atasan. Khususnya bagi pimpinan PT. PLN (Persero) Area Bengkulu untuk lebih memperhatikan serta melindungi karyawan jika terdapat hal yang menganggu

2. Work engagement pada PT. PLN (Persero) Area Bengkulu sudah baik namun sesuai dengan hasil penelitian pada kuesioner dalam pernyataan "saya tetap tekun melakukan tugas walaupun tidak selalu berjalan dengan baik" yang menjadi indikator terendah pada variabel ini, maka disarankan harus ditingkatkan lagi dengan cara antar sesama karyawan dan pimpinan PT. PLN (Persero) Area Bengkulu harus saling memberikan dorongan dan motivasi agar karyawan tetap 
tekun dalam menyelesaikan tugas walaupun tidak selalu berjalan dengan baik atau pekerjaan yang sulit sekalipun.

3. Kinerja karyawan PT. PLN (Persero) Area Bengkulu saat ini sudah cukup baik. Karyawan telah menjalankan tugas dan fungsinya masing-masing sesuai aturan dan ketentuan. Karyawan juga telah memenuhi tanggung jawabnya sehingga dapat menyelesaikan tugas-tugas yang diharapkan perusahaan, ini terlihat pada indikator nomor 7 yaitu "saya menyelesaikan tugas-tugas yang diharapkan perusahaan" menjadi indikator tertinggi pada variabel ini yang tergolong kategori sangat baik, maka harus dipertahankan. Sedangkan yang harus menjadi perhatian PT. PLN (Persero) Area Bengkulu yakni indikator nomor 6 "saya tidak peduli dengan aspek pekerjaan yang harus dilakukan" yang menjadi indikator dengan nilai terendah. Maka disarankan bagi pimpinan PT. PLN (Persero) Area Bengkulu perlu memperhatikan dan memberikan arahan para karyawan agar lebih mendahulukan aspek pekerjaaan yang harus dilakukan sehingga kinerja yang dihasilkan akan lebih optimal.

\section{Daftar Pustaka}

Abdillah, W. dan Jogiyanto. 2015. Partial Least Square (PLS) Alternatif Structural Equation Modeling (SEM) dalam Penelitian Bisnis. Ed.1. Yogyakarta: ANDI

Bakker, A. B., \& Demerouti, E.2007. The Job demands-resources model: State of the art. Journal of Managerial Psychology, 22, 309-328.

Bakker, A. B., \& Leiter, M. P. (2010). Work engagement a handbook of essential theory and research. New York: Psychology Press.

Bangun, Wilson. 2012. "Manajemen Sumber Daya Manusia". Jakarta: Erlangga. Cetakan Ke Tujuh PT. Remaja Rosdakarya, Bandung.

Baron, R.M., Kenny, D.A. 1986. The Moderator-Mediator Variabel Distinction in Social Psychological Research. Conseptual, Strategic and Statistical Considerations. Journal of Personality and Social Psychology.

Breevaart, K., Bakker, A. B., Demerouti, E., \& van den Heuvel, M. (2015)."Leadermember exchange, work engagement, and job performance." Journal of Managerial Psychology, 30(7), 754-770.

Dessler, Gary. 2009. Manajemen SDM buku 1. Jakarta: indeks

Gallup. 2013. Worldwide, 13\% of Employees Are Engaged at Work. https://news.gallup.com/poll/165269/worldwide-employees-engaged work.aspx.

Graen, G.B., Uhl-Bien, M., 1995. Relationship-based approach to leadership: Development of Leader-member exchange (LMX) theory of leadership over 25 years: Applying a multi-level multi-domain perspective. Leadership Quarterly 6, 219-247.

Li, Xiaobei, Sanders, K., \& Frenkel, S. (2012). "How leader-member exchange, work engagement and HRM consistency explain Chinese luxury hotel employees' job 
performance." International Journal of Hospitality Management, 31(4), 10591066.

Liden, R. C., \& Maslyn, J. M. 1998. Multi-dimensionality of leader-member exchange: An empirical assessment through scale development. Journal of Management, 24: 43-72.

Luthans, F. (2008). Organizational behaviour. New York: McGraw-Hill.

Mangkunegara, A.A. Anwar Prabu. 2013, Manajemen Sumber Daya Manusia Perusahaan. Bandung: PT. Remaja Rosdakarya.

Mathis, Robert L. \& John Harlod Jackson. 2006. Human Resource Management terjemahan. Edisi kesepuluh. Jakarta: Salemba Empat.

Schaufeli, Wilmar. 2013. What Is Engagement?. London: Routledge.

Schaufeli, W., Bakker, A. B. and Salanova, M. (2006). "The Measurement of work engagement with a short questionnaire: a cross-national study", Educational and Psychological Measurement, Vol. 66, pp. 701-716.

Sekaran, U. 2006. Metodologi Penelitian untuk Bisnis, Edisi 4, Buku 1. Jakarta: Salemba Empat.

Sekaran, Uma dan Roger Bougie. 2016. Research Methods for Business. Edisi Ketujuh. United Kingdom: John Wiley \& Sons.

Simanjuntak, P. J. 2011, Manajemen dan Evaluasi Kinerja, Jakarta: Fakultas Ekonomi UI.

Sugiyono. 2014. Metode Penelitian Kuantitatif Kualitatif dan R\&D. Bandung: Alfabeta. Research. Journal of Management.

Truckenbrodt, Yolanda. B. 2000. The relationship between leader-member exchange and comitment and organizational citizenship behavior. Research acquistion review quarterly 233-244.

Wibowo. 2013. Manajemen Kinerja. Jakarta: Rajawali Pers.

Williams, L. J. and Anderson, S. E. (1991), "Job satisfaction and organisational commitment as predictors of organisational citizenship and in-role behaviors", Journal of Management, Vol. 17 No. 3, pp. 601-617.

Yukl, A. Gary. (1998). Managerial leadership: A review of theory and research. Journal of Management. $15:$ 251-289. 